\title{
Acute Clinical Deterioration of Posterior Fossa Epidural Hematoma: Clinical Features, Risk Factors and Outcome
}

\author{
Tsung-Ming Su, MD; Tsung-Han Lee, MD; Tao-Chen Lee, MD; \\ Ching-Hsiao Cheng, MD; Cheng-Hsien Lu' ${ }^{1}, \mathrm{MD}$
}

Background: This study aimed to present experience in treating patients with posterior fossa epidural hematoma (PFEDH) and to discuss the risk factors, clinical features, and outcome in PFEDH patients with acute clinical deterioration (ACD).

Methods: Twenty-seven patients with PFEDH initially treated conservatively were evaluated. A comparison was made between patients with and without ACD during hospitalization.

Results: $\quad$ Eight of the 27 patients subsequently experienced ACD. Local traumatic findings, loss of consciousness due to injury, headache, and vomiting were the four most common clinical features of the 27 cases. Seven of the 8 patients with ACD had good recoveries and 1 died. Eighteen of the 19 patients without ACD had good recoveries, while 1 remained moderately disabled. Stepwise logistic regression demonstrated that the adjusted risk of ACD during hospitalization for patients with vomiting and an occipital fracture across the transverse sinus on computed tomography (CT) had odds ratios of $12.6(95 \%$ confidence interval $=1.03-152.37, p=0.047)$ and 8.8 $(95 \% \mathrm{CI}=1.02-75.95, p=0.048)$, respectively, compared with those without ACD.

Conclusion: This study demonstrated that an occipital fracture across the transverse sinus on $\mathrm{CT}$ and vomiting on presentation are risk factors for ACD during hospitalization. In this study, PFEDH patients including those with ACD had good outcomes. Further studies are necessary to clarify the clinical course and risk factors for the clinical deterioration of PFEDH patients and to establish a treatment strategy.

(Chang Gung Med J 2012;35:271-80)

Key words: acute clinical deterioration, epidural hematoma, posterior fossa

$\mathrm{P}$ osterior fossa epidural hematoma (PFEDH) is an uncommon complication of head injury. It accounts for approximately $0.3 \%$ of all craniocerebral injuries, ${ }^{(1)}$ and constitutes $2.7-11 \%$ of all intracranial epidural hematomas (EDH). ${ }^{(2-5)}$ Clinical diagnosis is difficult because of its relative rarity combined with the scarcity of early specific symptoms. Clinical progress may be silent and slow, but

From the Department of Neurosurgery; 'Department of Neurology, Kaohsiung Chang Gung Memorial Hospital and Chang Gung University College of Medicine, Kaohsiung, Taiwan.

Received: Oct. 7, 2010; Accepted: Dec. 28, 2011

Correspondence to: Dr. Cheng-Hsien Lu, Department of Neurology, Kaohsiung Chang Gung Memorial Hospital. No. 123, Dapi Rd., Niaosong Dist., Kaohsiung City 833, Taiwan (R.O.C.) Tel: 866-7-7317123 ext. 8011; Fax: 866-7-7318762;

E-mail: chlu99@ms44.url.com.tw 
the deterioration may be sudden because of compression of vital structures in the brain stem, usually without significant warning signs. This may cause devastating consequences if not promptly treated.

The recommended treatment for PFEDH is surgical evacuation immediately after diagnosis because the posterior fossa contains vital structures. However, since the introduction of computed tomography (CT), there has been an increasing number of cases of PFEDH treated conservatively with good results, both in children ${ }^{(6,7)}$ and in adults. ${ }^{(3)}$ The decision between surgery and observation is still a controversial matter.

PFEDH was once considered to have a longer clinical compensation period than supratentorial EDH. However, when clinical decompensation manifests, signs of brain stem compression may develop very rapidly. ${ }^{(5,8,9)}$ Therefore, intensive clinical and radiologic surveillance is mandatory in PFEDH patients treated conservatively in order to avoid any devastating consequences. This study presents our experience in treating patients with traumatic PFEDH and discusses risk factors, clinical features, and outcomes in those with acute clinical deterioration (ACD).

\section{METHODS}

\section{Study design}

From 1996 to 2008, 636 patients with traumatic EDH were diagnosed at the Kaohsiung Chang Gung Memorial Hospital. Of these, 48 had PFEDH (7.5\% of all EDH cases). A retrospective review of medical records and radiographs provided clinical and radiographic information. Twenty-one patients underwent immediate surgery because the PFEDH caused a significant mass effect and/or altered consciousness after adequate resuscitation. ${ }^{(3)}$ The other 27 accepted conservative treatment first because the PFEDH did not cause altered consciousness or a significant mass effect. $^{(3)}$ These 27 patients were enrolled in this study to investigate the risk factors, clinical features, and outcomes in PFEDH patients who had ACD. The protocol for conservative treatment included admission to the neurosurgical intensive care unit with continuous electrocardiographic and respiratory monitoring. Particular attention was paid to alteration in the level of consciousness. Hyperosmolar agents were given according to the clinical and radi- ographic findings. Follow-up CT scans were obtained at the time of ACD or one or two days after the initial CT scan. Conservative treatment management was immediately terminated and a craniotomy performed if the patient showed signs of ACD or a repeat CT scan showed a significant mass effect. ${ }^{(3,7)}$

\section{Clinical data}

For each patient, the clinical data, mechanism of head injury, clinical manifestations, neurologic findings, clinical course, and operative findings were carefully reviewed from the medical records. The clinical course was classified according to the proposal of Hooper ${ }^{(10)}$ as acute (onset of symptoms within the first 24 hours of trauma), subacute (after 24 hours to the 7th day after trauma), and chronic (later than 7 days after trauma).

The Glasgow Coma Scale (GCS) score was used to assess the level of consciousness on admission and to measure the clinical status after admission. ACD was defined as a sudden deterioration in the GCS (decrease of best motor response score $\geq 1$ and/or decrease of GCS score $\geq 2$ ) within a few hours combined with enlargement of the PFEDH on repeat CT scan. Operative findings and details, including the operative procedure, presence of a skull fracture overlying the PFEDH, course of the fracture, location and size of the PFEDH, and bleeding sources of the PFEDH were reviewed. The functional outcome was evaluated 6 months after the injury using the Glasgow Outcome Scale score as follows: 1 = death; 2 = persistent vegetative state; 3 $=$ severe disability; $4=$ moderate disability; and $5=$ good recovery. ${ }^{(11)}$

\section{Radiographic data}

Radiographic data, including the volume and mass effect of the PFEDH, presence of a skull fracture overlying the PFEDH, course of the fracture, and associated brain injury, were reviewed. The EDH volume was measured by the empirical formula of volume ( 0.5 height $x$ depth $x$ length) on the basis of distance measurements of the depth and length on the CT slice having the largest area of the clot. ${ }^{(12)}$ When the hematoma extended beyond the posterior fossa, the PFEDH volume was measured on the CT slice $1 \mathrm{~cm}$ cephalad to the mastoid bone. ${ }^{(13)}$

The degree of midline shift was determined by measuring the deviation of the center of the fourth 
ventricle to the line between the occipital protuberance and the midpoint of the clivus, or the midpoint of the sphenoid sinus on CT scan. ${ }^{(13)}$ Obliteration of the perimesencephalic cisterns (especially the quadrigeminal cistern), compression and/or displacement of the fourth ventricle, presence of hydrocephalus, and the degree of midline shift were carefully studied to assess the mass effect of the hematoma. ${ }^{(3)}$

The presence and course of a skull fracture was determined by radiographic or operative findings. Associated brain injury was defined as significant brain injuries such as severe subarachnoid hemorrhage or intraventricular hemorrhage, supratentorial epidural or subdural hematoma, focal brain contusion more than $2 \mathrm{~cm}$ in diameter or multifocal brain contusion.

\section{Statistical analysis}

Two separate statistical analyses were performed. First, risk factors for ACD during hospitalization were determined. Baseline clinical data including gender and clinical manifestations between patients with and without ACD, were analyzed by the chi-square test or Fisher's exact test. The mean age and GCS on admission, and the median hematoma thickness and volume were compared between the two patient groups using Student's $t$ - test or the Mann-Whitney Test.

Second, stepwise logistic regression was used to evaluate relationships between baseline clinical factors and ACD during hospitalization, with adjustments made for other potential confounding factors. Only variables with a strong association with ACD $(p<0.05)$ were included in the stepwise logistic regression model. All statistical analyses were conducted using the SAS software package, version 9.1 (2002, SAS Statistical Institute, Cary, North Carolina, U.S.A.).

\section{RESULTS}

\section{Patient characteristics}

Twenty-seven PFEDH patients initially treated conservatively were evaluated. Among them, eight subsequently suffered ACD. The clinical manifestations and radiographic findings of these eight patients are described in Table 1. Comparisons of clinical features and radiographic findings between patients with and those without ACD are summarized in Table 2.

The patients with ACD were 14-57 years old (mean: $35.9 \pm 17.6$ years), while the 19 patients without ACD were 1-59 years old (mean: $25.3 \pm$ 17.0 years). There were six male and two female patients with ACD, and there were 12 male and seven female patients without ACD.

The causes of injury in patients with ACD were vehicular accidents in seven and a fall in one. In patients without ACD, the causes were vehicular accidents in 11 patients, falls in seven, and an assault in one.

\section{Clinical manifestations}

Five of the eight patients with ACD and nine of the 19 patients without ACD lost consciousness at the time of injury. All of the patients with ACD and 17 of the 19 patients without ACD had local trauma findings (swelling, ecchymosis, and/or lacerations) over the occipital scalp. Headache was a complaint in four of the patients with ACD and in 14 of the patients without ACD. Vomiting was noted in seven patients without ACD and in seven patients just before ACD. Only three patients without ACD manifested cerebellar signs.

\section{Radiographic findings}

Computed tomography on admission showed PFEDH in seven of the 8 patients with ACD and in 17 of the 19 patients without ACD (Fig. 1 and 2). One patient with ACD and 2 patients without ACD showed no significant findings in the posterior fossa on initial CT. All patients with ACD had occipital bone fractures on CT scan, whereas two of the 19 patients without ACD did not. Occipital fracture crossing the transverse sinus was noted in six patients with ACD and in five patients without ACD. Three patients with ACD had a hematoma thickness $>15 \mathrm{~mm}$, which was also seen in four patients without ACD. A hematoma volume $>10 \mathrm{ml}$ was noted in three patients with ACD and four patients without ACD.

A midline shift $>5 \mathrm{~mm}$ was noted in two patients with ACD and one patient without ACD. Obliteration of the perimesencephalic cisterns was noted in four patients with ACD and six patients without ACD. Three patients with ACD and seven without ACD showed compression and/or displace- 
Table 1. Clinical and Radiographic Features of Patients with Posterior Fossa Epidural Hematoma and Acute Clinical Deterioration

\begin{tabular}{|c|c|c|c|c|c|c|c|c|}
\hline Case & $\begin{array}{l}\text { Age/ } \\
\text { Sex }\end{array}$ & Mechanism & $\begin{array}{c}\text { GCS on } \\
\text { admission } \\
\text { and time* }\end{array}$ & $\begin{array}{c}\text { Clinical } \\
\text { manifestations }\end{array}$ & $\begin{array}{c}\text { GCS on } \\
\text { deterioration } \\
\text { and time }\end{array}$ & $\begin{array}{l}\text { Initial CT } \\
\text { findings }\end{array}$ & $\begin{array}{l}\text { Bleeding } \\
\text { source }\end{array}$ & GOS \\
\hline 1 & $57 / \mathrm{F}$ & $\begin{array}{c}\text { Traffic } \\
\text { accident }\end{array}$ & 13 at $1 \mathrm{hr}$ & $\begin{array}{l}\text { Local trauma findings, } \\
\text { headache, vomiting }\end{array}$ & 10 at $4 \mathrm{hr}$ & Fr, CS, SE, C, V & $\begin{array}{l}\text { Transverse } \\
\text { sinus }\end{array}$ & 5 \\
\hline 2 & $14 / \mathrm{M}$ & $\begin{array}{c}\text { Traffic } \\
\text { accident }\end{array}$ & 14 at $1 \mathrm{hr}$ & $\begin{array}{l}\text { Local trauma findings, } \\
\text { headache, vomiting }\end{array}$ & 9 at $3 \mathrm{hr}$ & $\begin{array}{c}\text { Fr, CS, right } \\
\text { parietal contusion }\end{array}$ & Unidentified & 5 \\
\hline 3 & $37 / \mathrm{M}$ & Fall & 14 at $1 \mathrm{hr}$ & $\begin{array}{c}\text { Local trauma } \\
\text { findings, vomiting }\end{array}$ & 6 at $2 \mathrm{hr}$ & $\begin{array}{l}\text { Fr, C, V, H, left } \\
\text { frontal contusion }\end{array}$ & Unidentified & 5 \\
\hline 4 & $50 / \mathrm{M}$ & $\begin{array}{c}\text { Traffic } \\
\text { accident }\end{array}$ & 7 at $4 \mathrm{hr}$ & $\begin{array}{l}\text { Local trauma } \\
\text { findings }\end{array}$ & 4 at $10 \mathrm{hr}$ & $\begin{array}{c}\text { Fr, CS, right } \\
\text { subdural hematoma, } \\
\text { no PFEDH }\end{array}$ & $\begin{array}{l}\text { Transverse } \\
\text { sinus }\end{array}$ & 1 \\
\hline 5 & $48 / \mathrm{M}$ & $\begin{array}{c}\text { Traffic } \\
\text { accident }\end{array}$ & 13 at $2 \mathrm{hr}$ & $\begin{array}{c}\text { Local trauma } \\
\text { findings, vomiting }\end{array}$ & 7 at $5 \mathrm{hr}$ & $\begin{array}{c}\text { Fr, CS, right } \\
\text { subdural hematoma }\end{array}$ & $\begin{array}{l}\text { Fractured } \\
\text { bone }\end{array}$ & 5 \\
\hline 6 & $48 / \mathrm{F}$ & $\begin{array}{c}\text { Traffic } \\
\text { accident }\end{array}$ & 13 at $4 \mathrm{hr}$ & $\begin{array}{c}\text { Local trauma } \\
\text { findings, headache, } \\
\text { vomiting }\end{array}$ & 9 at $6 \mathrm{hr}$ & $\mathrm{Fr}$ & $\begin{array}{l}\text { Transverse } \\
\text { sinus }\end{array}$ & 5 \\
\hline 7 & $17 / \mathrm{M}$ & $\begin{array}{c}\text { Traffic } \\
\text { accident }\end{array}$ & 14 at $3.5 \mathrm{hr}$ & $\begin{array}{c}\text { Local trauma } \\
\text { findings, vomiting }\end{array}$ & 6 at $10 \mathrm{hr}$ & Fr, CS, SE, C & $\begin{array}{l}\text { Transverse } \\
\text { sinus }\end{array}$ & 5 \\
\hline 8 & $16 / \mathrm{M}$ & $\begin{array}{c}\text { Traffic } \\
\text { accident }\end{array}$ & 13 at $1 \mathrm{hr}$ & $\begin{array}{c}\text { Local trauma } \\
\text { findings, headache, } \\
\text { vomiting }\end{array}$ & 6 at $8 \mathrm{hr}$ & Fr, CS, SE, C, V, H & Unidentified & 5 \\
\hline
\end{tabular}

Abbreviations: GCS: Glasgow Coma Scale; CT: computed tomography; GOS: Glasgow Outcome Scale, $1=$ death, $2=$ persistent vegetative state, 3 = severe disability, 4 = moderate disability, 5 = good recovery; M: male; F: female; hr: hours; Fr: fracture of the occipital bone; CS: fracture cross the transverse sinus; SE: supratentorial extension of posterior fossa epidural hematoma; C: obliteration of the perimesencephalic cisterns; V: compression and/or displacement of the fourth ventricle; H: hydrocephalus; PFEDH: posterior fossa epidural hematoma; *: time interval between injury and admission; $\uparrow:$ time interval between injury and acute clinical deterioration; $\$$ : CT findings on admission.

ment of the fourth ventricle on initial CT. Hydrocephalus was noted in two patients with ACD and one without ACD.

Of the eight patients with $A C D$, three showed supratentorial extension of the PFEDH. Associated brain injury was noted in four patients with ACD. Among these, two had contusion hemorrhages and two had concurrent supratentorial subdural hematomas (SDH). Seven patients without ACD had associated brain injuries. Among them, three had concurrent supratentorial EDH, one had a contusion hemorrhage, and two had supratentorial SDH.

\section{Management and outcome}

All patients with ACD underwent emergency surgery to evacuate the hematoma immediately after the onset of ACD. One patient underwent a craniectomy to evacuate the supratentorial SDH first, and then posterior fossa surgery at the time of ACD. The bleeding source was the transverse sinus in four 
Table 2. Comparison of Clinical Features and Radiographic Findings in Patients with Posterior Fossa Epidural Hematoma

\begin{tabular}{|c|c|c|c|c|c|}
\hline & $\begin{array}{c}\text { Without acute } \\
\text { clinical deterioration } \\
(\mathrm{N}=19)\end{array}$ & $\begin{array}{l}\text { With acute clinical } \\
\text { deterioration } \\
(\mathrm{N}=8)\end{array}$ & $p$-value & OR & $95 \% \mathrm{CI}$ \\
\hline Sex (Male/female) & $12 / 7$ & $6 / 2$ & 0.676 & 1.75 & $0.28-11.15$ \\
\hline Mean age (year) & $25.3 \pm 17.0$ & $35.9 \pm 17.6$ & 0.154 & & \\
\hline $\begin{array}{l}\text { Median (IQR) interval between injury and } \\
\text { admission (hour) }\end{array}$ & $3.0(1.0,6.0)$ & $1.5(1.0,3.9)$ & 0.276 & & \\
\hline \multicolumn{6}{|l|}{ Causes of injury } \\
\hline Fall & 7 & 1 & 0.319 & & \\
\hline Assault & 1 & 0 & & & \\
\hline Traffic accident & 11 & 7 & & & \\
\hline Mean GCS on admission & $13.0 \pm 2.8$ & $12.6 \pm 2.3$ & 0.74 & & \\
\hline Type of injury (acute/subacute) & $15 / 4$ & $8 / 0$ & 0.285 & 0.652 & $0.48-0.88$ \\
\hline \multicolumn{6}{|l|}{ Radiographic findings at presentation } \\
\hline Occipital bone fracture & 17 & 8 & 1.0 & 1.47 & $1.12-1.92$ \\
\hline Fracture crossing transverse sinus & 5 & 6 & 0.033 & 8.4 & $1.26-56.07$ \\
\hline Median (IQR) hematoma thickness (mm) & $14.0(9.5,17.5)$ & $14.0(4.0,17.0)$ & 0.677 & & \\
\hline Median (IQR) hematoma volume (ml) & $6.0(3.1,9.6)$ & $10.0(2.0,12.0)$ & 0.256 & & \\
\hline Median (IQR) midline shift (mm) & $0(0,0)$ & $1.0(0,5.8)$ & 0.142 & & \\
\hline Perimesencephalic cistern obliteration & 6 & 4 & 0.415 & 2.17 & $0.40-11.74$ \\
\hline Fourth ventricle displacement & 7 & 3 & 1.0 & 1.03 & $0.19-5.68$ \\
\hline Hydrocephalus & 1 & 2 & 0.20 & 6.0 & $0.46-78.56$ \\
\hline Supratentorial extension of PFEDH & 1 & 3 & 0.065 & 10.8 & $0.91-127.75$ \\
\hline \multicolumn{6}{|l|}{ Clinical features } \\
\hline Consciousness loss at injury & 9 & 5 & 0.678 & 1.852 & $0.34-10.05$ \\
\hline Local trauma findings & 17 & 8 & 1.0 & 1.47 & $1.12-1.92$ \\
\hline Headache & 14 & 4 & 0.375 & 0.357 & $0.06-2.0$ \\
\hline Vomiting & 7 & 7 & 0.033 & 12.0 & $1.21-118.89$ \\
\hline Cerebellar signs & 3 & 0 & 0.532 & 0.667 & $0.51-0.89$ \\
\hline
\end{tabular}

Abbreviations: GCS: Glasgow Coma Scale; OR: odds ratio; CI: confidence interval; IQR: interquartile range; PFEDH: posterior fossa epidural hematoma.

patients and fractured bone in one. In three cases, the bleeding source could not be identified.

Five of the 19 patients without ACD underwent surgery because of enlargement of the PFEDH on follow-up CT and/or persistent clinical manifestations. The bleeding source was the transverse sinus in one patient. In four cases, the bleeding source could not be identified. In two patients, the occipital fracture crossed the transverse sinus, which was not demonstrated on CT.

Seven of the eight patients with ACD had good recoveries and one died. The patient who died suf- 

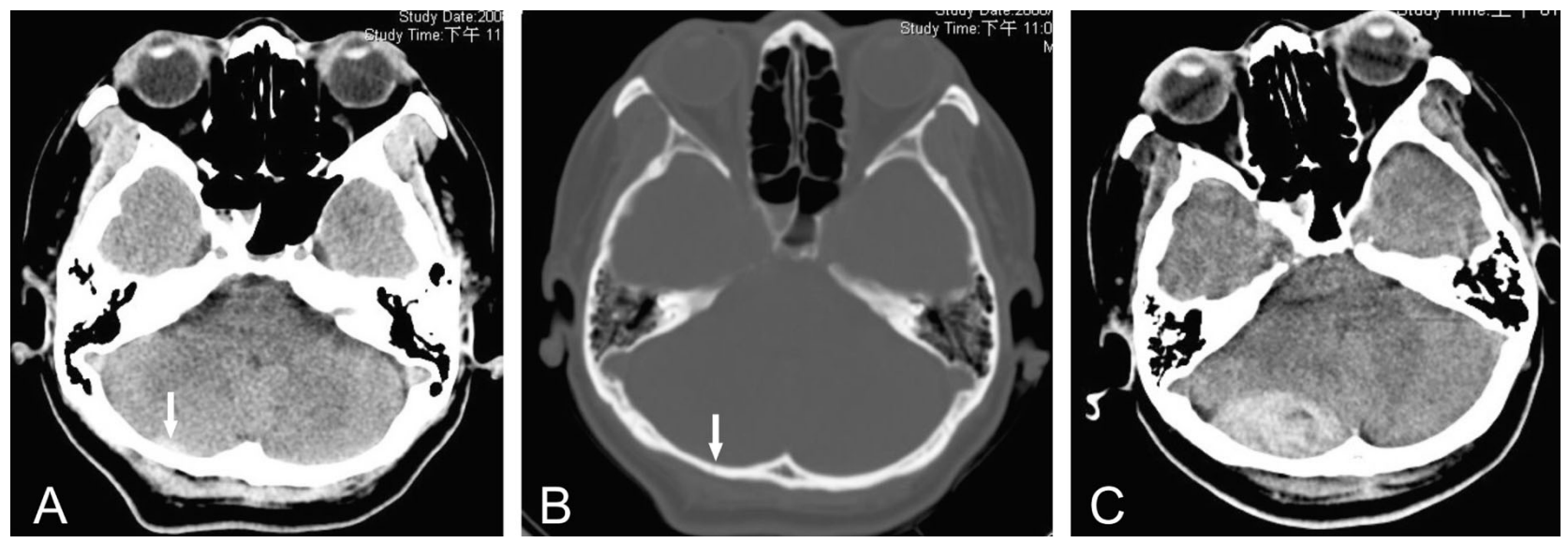

Fig. 1 (A) Computed tomography (CT) scan shows a thin layer of intracranial hematoma in the posterior fossa (arrow), with a skull fracture (B) in the occipital region (arrow). (C) Repeat CT shows a large posterior fossa epidural hematoma with a severe mass effect.
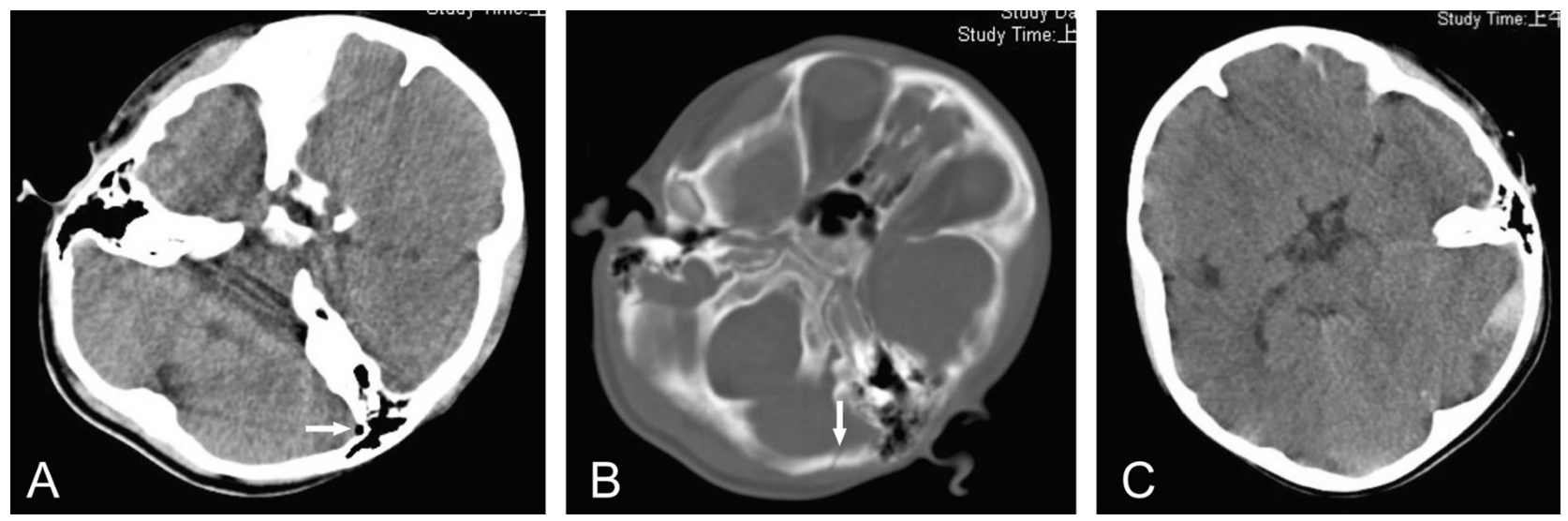

Fig. 2 (A) Computed tomography (CT) shows minimal pneumocephalus in the posterior fossa (arrow), with a skull fracture (B) in the occipital region (arrow). (C) Repeat CT demonstrates a posterior fossa epidural hematoma with obliteration of the perimesencephalic cisterns.

fered a supratentorial SDH with a marked mass effect. Eighteen of the 19 patients without ACD had good recoveries while one remained moderately disabled.

\section{Statistical analysis}

Comparisons of clinical features and neuroimaging findings between patients with and those without ACD during hospitalization are listed in Table 2. Statistical analysis of the baseline clinical manifestations and neuroimaging findings between the two patient groups revealed that vomiting ( $p=$ 0.033 ) and an occipital fracture crossing the transverse sinus $(p=0.033)$ were significant factors.
Variables used in the stepwise logistic regression model included vomiting at presentation and an occipital fracture crossing the transverse sinus. After analysis of all the aforementioned variables, only vomiting at presentation $(p=0.047$, odds ratio [OR] $=12.55,95 \%$ confidence interval $[\mathrm{CI}]=1.03-$ $152.37)$ and an occipital fracture crossing the transverse sinus $(p=0.048, \mathrm{OR}=8.80,95 \% \mathrm{CI}=1.02$ 75.95) were independently associated with ACD.

\section{DISCUSSION}

Posterior fossa epidural hematoma accounted for $7.5 \%$ of the EDH in this study. Nineteen of the 21 
patients who underwent immediate surgery after diagnosis recovered well while one was moderately disabled and one died. In patients first treated conservatively, 25 achieved excellent recoveries without deficit, one was moderately disabled and one died despite surgery after ACD. Overall mortality was $4.1 \%$, which was comparable to previous series. ${ }^{(3,5,8)}$ The outcome of PFEDH was mainly influenced by the level of consciousness immediately before surgery. ${ }^{(3,5,14)}$

In this study, two of the three cases with a GCS score of 4 died while the other one had moderate disability. However, ACD did not seem related to poor outcome because seven of the patients with ACD recovered well. This fact indicates that neurosurgeons must intensively monitor PFEDH patients treated conservatively and treat deteriorating patients promptly before irreversible brain damage develops.

A negative CT scan does not rule out the possibility of PFEDH nor does the absence of occipital fracture. Pozzati and colleagues detected PFEDH on the second CT scan after neurologic deterioration in two patients whose initial CT scans were negative. ${ }^{(8)}$ In addition, they found the PFEDH on repeat CT scans of two patients after surgery for supratentorial hematomas. Three of the 27 patients first treated conservatively in the current study did not show PFEDH on initial scans. In a patient who underwent surgery for supratentorial SDH, PFEDH was detected on repeat $\mathrm{CT}$ after $\mathrm{ACD}$. In the current study, two patients did not have skull fractures on CT scans. Thus, it should be kept in mind that repeat CT scan may be necessary when neurologic deterioration occurs in a patient with occipital trauma in order to detect the presence of delayed PFEDH, even in the absence of an occipital fracture.

The mechanism by which PFEDH causes a rapidly increasing mass effect and clinical deterioration is still not well understood. Acute hydrocephalus secondary to obstruction of the cerebrospinal fluid pathway by the PFEDH may be a cause of clinical deterioration. However, hydrocephalus was not a risk factor for ACD in this study. Vomiting has been reported to be a risk factor for ACD in patients with PFEDH. ${ }^{(15)}$ However, the precise mechanism of posttraumatic vomiting is still unknown. Stimulation of the vomiting center in the reticular formation of the lateral medulla due to impact may be the cause. ${ }^{(16)}$

In the current study, vomiting and a fracture crossing the transverse sinus were the risk factors for ACD. A possible explanation may be that the trauma resulted in a fracture that crossed the transverse sinus, which in turn caused tearing of the venous sinus with subsequent venous bleeding. An acute increase in venous pressure caused by vomiting aggravated venous bleeding and resulted in rapid hematoma expansion, then ACD. ${ }^{(15)}$ However this postulate cannot explain the mechanism of ACD in two cases cited in this study because their fractures did not cross the transverse sinus.

Concurrent intracranial traumatic lesions with associated increased intracranial pressure have been assumed to be a "protective mechanism" responsible for the delayed onset of EDH. ${ }^{(17,18)}$ Therefore, measures such as decompressive surgery and use of hyperosmolar agents to reduce the increased intracranial pressure may release the tamponade effect and contribute to the formation of delayed EDH. ${ }^{(18,19)} \mathrm{In}$ this study, three patients who underwent surgery for supratentorial hematomas showed enlarged PFEDH on follow-up CT scans.

Significant changes in post-traumatic intracranial hematomas and the appearance of new hematomas can occur without changes in the clinical status of the patient. ${ }^{(20)}$ One of the major goals of neurosurgeons is the early detection and treatment of new mass lesions that require surgery before clinical deterioration. In this study, five patients showed enlargement of the PFEDH on a second CT scan, but without clinical deterioration. Therefore, we recommend a timely repeat CT examination in patients with PFEDH to detect an enlarged PFEDH before clinical deterioration, and prompt intervention, regardless of neurological status. According to a previous study, ${ }^{(20)}$ repeating CT within first day after the initial scan seems reasonable to evaluate the status of the PFEDH. If CT shows enlargement of a PFEDH which causes a significant mass effect, craniotomy is strongly recommended to avoid clinical deterioration and devastating consequences.

The management of PFEDH remains controversial. The recommended treatment is surgical evacuation immediately after diagnosis, since the posterior fossa contains vital structures. However, Kawakami et al reported two PFEDH patients who were neurologically intact with a mass effect seen on CT. ${ }^{(6)}$ They treated the patients conservatively and obtained good results. Wong suggested reserving "expectant" treat- 
ment for those with a PFEDH volume less than 10 $\mathrm{ml}$, a thickness less than $15 \mathrm{~mm}$, a midline shift less than $5 \mathrm{~mm}$, and no significant intracranial hematoma elsewhere on CT. ${ }^{(13)}$ Bozbuga and colleagues thought that obliteration of the perimesencephalic cisterns and compression of the fourth ventricle were evidence of brain stem compression which occurred secondary to the sum effect of the thickness of the hematoma, primary brain injury, brain edema, and other intracranial pathologies. ${ }^{(3)}$ For them, this could be a simple and effective way to evaluate the mass effect and determine the need for surgical evacuation. They preferred surgical treatment for those patients with a marked mass effect on the perimesencephalic cisterns and fourth ventricle. We think further studies are necessary to clarify the clinical course and risk factors for the clinical deterioration of PFEDH patients. However, if the PFEDH causes a significant mass effect, surgical intervention still seems reasonable to avoid devastating consequences, regardless of the neurological status.

There were several limitations in this study. First, this is a retrospective study and the management of patients with PFEDH was not randomized, which may influence the results. Other factors including neurological status, neurological deterioration or improvement, size of the hematoma, mass effect, and time since injury may also have influenced surgical decision-making. However, it is difficult to conduct a randomized, prospective study because the treatment strategy for PFEDH remains a controversial matter and its clinical course varies. Second, CT imaging may fail to delineate the presence of a fracture and the course of the fracture clearly because of partial volume effects and pixel size. A skull fracture or a fracture crossing the transverse sinus may then be missed, confounding the results. As the sample size in this study was not large, the numbers of variables considered for multiple logistic regression analysis was small. Furthermore, based on the stepwise procedures, only two variables were selected as important predictive variables of outcomes.

This study demonstrates that vomiting and an occipital fracture crossing the transverse sinus on CT are risk factors for ACD during hospitalization. The outcome of PFEDH was good, even in patients with ACD. Further studies are necessary to clarify the clinical course and risk factors for the clinical deteri- oration of PFEDH patients. Close clinical and radiographic monitoring is mandatory in patients initially treated conservatively to avoid devastating consequences, especially in those who vomit repeatedly or have an occipital fracture across the transverse sinus.

\section{REFERENCES}

1. Campbell E, Whitfield RD, Greenwood R. Extra-dural hematomas of the posterior fossa. Ann Surg 1953;138: 509-17.

2. Ammirati M, Tomita T. Posterior fossa epidural hematoma during childhood. Neurosurgery 1984;14:5414.

3. Bozbuga M, Izgi N, Polat G, Gurel I. Posterior fossa epidural hematomas: observations on a series of 73 cases. Neurosurg Rev 1999;22:34-40.

4. Malik NK, Makhdoomi R, Indira B, Shankar S, Sastry K. Posterior fossa extra-dural hematoma: our experience and review of the literature. Surg Neurol 2007;68:155-8.

5. Neubauer UJ. Extra-dural haematoma of the posterior fossa. Twelve years experiences with CT-scan. Acta Neurochir 1987;87:105-11.

6. Kawakami Y, Tamiya T, Tanimoto T, Shimamura Y, Hattori S, Ueda T, Ishida T. Non-surgical treatment of posterior fossa epidural hematoma. Pediatr Neurol 1990;6:112-8.

7. Pang D, Horton JA, Herron JM, Wilberger JE Jr, Vries JK. Non-surgical management of extradural hematomas in children. J Neurosurg 1983;59:958-71.

8. Pozzati E, Tognetti F, Cavallo M, Acciarri N. Extra-dural hematomas of the posterior cranial fossa. Observations on a series of 32 consecutive cases treated after the introduction of computed tomography scanning. Surg Neurol 1989;32:300-3.

9. Stone JL, Schaffer L, Ramsey RG, Moody RA. Epidural hematomas of the posterior fossa. Surg Neurol 1979;11: 419-24.

10. Hooper RS. Extra-dural haemorrhages of the posterior fossa. Br J Surg 1954;42:19-26.

11. Jennett B, Bond M. Assessment of outcome after severe brain damage: a practical scale. Lancet 1975;1:480-4.

12. Peterson OF, Espersen JO. Extra-dural hematomas: measurement of size by volume summation on CT scanning. Neuroradiology 1984;26:363-7.

13. Wong CW. The CT criteria for conservative treatment but under close clinical observation - of posterior fossa epidural haematomas. Acta Neurochir 1994;126:124-7.

14. Roda JM, Gimenez D, Perez-Higueras A, Blazquez MG, Perez-Alvarez M. Posterior fossa epidural hematomas: a review and synthesis. Surg Neurol 1983;19:419-24.

15. Hayashi T, Kameyama M, Imaizumi S, Kamii H, Onuma T. Acute epidural hematoma of the posterior fossa - cases of acute clinical deterioration. Am J Emerg Med 
2007;25:989-95.

16. Nee PA, Hadfield JM, Yates DW, Faragher EB. Significance of vomiting after head injury. J Neurol Neurosurg Psychiatry 1999;66:470-3.

17. Riesgo P, Piquer J, Botella C, Orozco M, Navarro J, Cabanes J. Delayed extra-dural hematoma after mild head injury: report of three cases. Surg Neurol 1997;48:226-31.

18. Su TM, Lee TH, Chen WF, Lee TC, Cheng CH. Contralateral acute epidural hematoma after decompres- sive surgery of acute subdural hematoma: clinical features and outcome. J Trauma 2008;65:1298-302.

19. Thibodeau M, Melanson D, Ethier R. Acute epidural hematoma following decompressive surgery of a subdural hematoma. Can Assoc Radiol J 1987;38:52-3.

20. Servadei F, Nanni A, Nasi MT, Zappi D, Vergoni G, Giuliani G, Arista A. Evolving brain lesions in the first 12 hours after head injury: analysis of 37 comatose patients. Neurosurgery 1995;37:899-907. 


\title{
後腦窩之硬腦膜外血腫之急性臨床惡化： 臨床特徵、危險因子及瘾後
}

\author{
蘇宗明 李宗翰 李道眞 鄭境効 盧成害
}

背景：本研究主要目的爲報告後腦窩之硬腦膜外血腫之治療經驗, 並探討後腦窩硬腦膜外 血腫病人臨床急性惡化之臨床特徵、危險因子及癒後。

方 法: 研究對象爲二十七個一開始接受保守療法之後腦窩硬腦膜外血腫病人, 比較發生急 性臨床惡化之病人與未發生急性臨床惡化之病人之臨床表現及影像結果。

結 果 : 二十七個一開始接受保守療法之後腦窩硬腦膜外血腫病人中, 入個病人發生急性臨 床檼化。局部外傷表現、意識丧失、頭痛及嘔吐爲最常見之臨床表現。在八個發生 急性惡化之病人, 七個病人恢復良好, 但一個病人不幸死亡。在十九個沒有發生急 性悪化之病人, 十八個病人恢復良好, 一個病人遺留中等程度之神經障礙。統計分 析發現嘔吐及枕骨骨折通過横賽爲發生急性臨床惡化之危險因子。

結 論：此研究發現嘔吐及枕骨骨折通過横賔爲後腦窩硬腦膜外血腫病人發生急性臨床惡化 之危險因子。後腦窝硬腦膜外血腫通常癒後良好, 即使發生急性臨床惡化。目前需 要進一步研究來鳌清後腦窩硬腦膜外血腫病人發生急性臨床惡化之臨床進展及危險 因子, 並建立治療策略。

(長庚醫誌 2012;35:271-80)

關鍵詞：急性臨床惡化, 硬腦膜外血腫, 後腦窩 